\title{
How did our ancestors first become bipedal animals and then homo sapiens?
}

\begin{abstract}
The problems indicated in the title are interrelated. The systematic approach leads to the conclusion that the initial condition for the transformation of the domination system (biological hierarchy) into a system of social relations (social hierarchy) is the acquisition by hominids of the ability of an armed struggle each other. This struggle required the release of the hands from the function of locomotion. Thus, the problem of the emergence of bipedalism in humans finds a solution within the framework of the problem of anthroposociogenesis. The emergence of the human way of life is associated with the practice of the peaceful division of prey among all members of the hominid band. The difference in the principles of dividing has created a dispersion of the levels of combat efficiency of hominids bands and a permanent struggle among them. The consequence of this struggle was the group social-natural selection of communities, which was humanizing man's communities.
\end{abstract}

Keywords: hominid, system approach, bipedalism, domination, armed struggle, homo sapiens, human lifestyle, social-natural selection
Volume 6 Issue I - 202 I

\section{Sergey Peruanskiy \\ Doctor of Physical and Mathematical Sciences, Science Reviewer \\ of the Bulletin of the Russian Philosophical Society, Russia}

Correspondence: Sergey Peruanskiy, Doctor of Physical and Mathematical Sciences, Science Reviewer of the Bulletin of the Russian Philosophical Society, 8-2-534 Ak Koroleva Str. Moscow, 129515 Russian, Email ivan534@mail.ru

Received: February 26, 2021 | Published: August 27, 202 |

\section{Introduction}

Problems of human and bipedalism origin occupy a special place in anthropology. An outstanding comrade-in-arms, Darwin E. Haeckel, in his famous speech at the Congress of Zoologists in Cambridge in 1898, spoke about the issues of zoology: "Of these issues, none represents such great common interest, such a profound philosophical significance as the question of the origin of man, it is the colossal "question of all questions". ${ }^{1}$ From this we can conclude that the problem of human origin is the central problem of anthropology. Many scientists have written about the special place in anthropology of the problem of the origin of bipedalism in humans. According to D. Gebo, "the origin of human bipedalism is one of the most persistent mysteries of paleoanthropology". ${ }^{2}$ Russian scientist L. Vishnyatsky writes: "Despite the fact that only very few topics related to the study of anthropogenesis have caused as much discussion as the origin of bipedalism causes them, this event remains a mystery, being a truly 'cursed question' of paleoanthropology". ${ }^{3}$ Encyclopedia Britannica states: "There are many theories that try to explain why people are bipedal, but none is completely satisfactory." According to Encyclopedia Britannica, "because bipedalism leaves hands free, some scientists, including Darwin, associated it with the use of tools, especially tools for protection and hunting, i.e. weapons. This theory is problematic in that the earliest stone artifacts appeared only about 3.3 million years ago, much later after the hominids became bipedal, which requires the assumption that earlier tools were made of wood or other perishable materials". ${ }^{4}$ Explaining the origin of the human way of life is the most important issue in the composition of the problem of human origin.

The overriding question is: where is the border between animals and humans? The difficulty of this distinction was emphasized by the outstanding anthropologist L. Leakey: "Just what is man? There was a time when our definition of man was: "Man begins at that state of primate evolution when the creatures begin to make tools to a set and regular pattern." That definition was rendered invalid a few years ago by the research of Jane van Lawick-Goodall, who found that chimpanzees living under natural wild conditions in Tanzania, habitually made and used simple tools of perishable material, for a variety of purposes. For the time being we are inclined to define man as "the primate that makes cutting tools"; but I fear this definition is not necessarily a good one". ${ }^{5}$ L. Leakey is right: the fundamental difference among animals and humans must be sought not in the peculiarities of tools, but in the peculiarities of the relationship among individuals. "The essence of man is no abstraction inherent in each single individual. In its reality it is the ensemble of the social relations". ${ }^{6}$ Based on this position, Soviet anthropologists considered anthropogenesis and sociogenesis as a single process of anthroposociogenesis. The Soviet anthropologist Yu. Semenov wrote: "The process of the formation of a person and the process of the formation of society are not two independent processes, but two sides of one single process - the process of the formation of a person and society (anthropo-sociogenesis)". ${ }^{7}$ This point of view is accepted by modern anthropology. Thus, in a book Science for All Americans says: "The most important questions in philosophical anthropology are: anthropo-sociogenesis, sense of life, freedom and necessity in human actions, etc". ${ }^{8}$

\section{Material and method}

To answer the questions posed in the title of the article, a systematic approach was applied to the analysis of a model of a system of relationships in bands of hominids, built by anthropologists on the basis of primatological data. M. Edey writes about the system of relationships in hominid bands: "Whether in looking for a hominid model, one selects the genetically close chimp or ecologically close baboon, one does find dominance as a structuring influence in social life". ${ }^{9}$ The dominant system of relationships is a biological hierarchy. Its parameter of order is the physical strength of individuals. The order of the system under the biological hierarchy is that the leader of the band is the first who possess the prey and eats, then the other members of the band get access to the prey in decreasing order of physical strength. In communities of people, there is a social hierarchy - a system of relationships, the order parameter of which is the merits of individuals to the community; it does not depend on the 
physical strength of individuals. Thus, the problem of the origin of the human way of life can be concretized as the problem of transforming the system of biological hierarchy into a system of social hierarchy. According to the systems approach, the stages of evolution for all systems are the same, regardless of the nature of the system. ${ }^{10}$

The emergence of a new system begins with the appearance of a perturbing factor that prevents the order parameter from maintaining the previous order of the system. This makes the system unstable. The highest stage of instability is a state called a bifurcation point. There are only two ways out of this state: disintegration of the system or an abrupt transition into a qualitatively new system with a different order parameter. The standard nature of the stages of evolution of systems makes it possible to simplify the solution of our problem by dividing it into several subtasks. First of all, it is necessary to understand what new ability acquired by hominids has become a disturbing factor for physical strength as an order parameter. What "innovative" actions, carried out thanks to this ability, have led the biological hierarchy to instability? These "pioneering" actions of the hominids, which put an end to the biological hierarchy, bringing it to a point of bifurcation, can be seen as the last animal act. The very fact of the existence of mankind shows that our ancestors not only brought the biological hierarchy to the point of bifurcation, but also found a way out of this critical state, creating a qualitatively new system of social hierarchy. This raises the second question: what actions of hominids should be considered as the initial historical act from which the history of mankind began? Finally, the third question related to understanding the emergence of the human way of life: what is the mechanism of humanization, i.e., the evolution of man from the original historical act to the social relations of our day?

\section{The last animal act}

The biological hierarchy is the law of natural selection: in the competition for objects of needs, the strongest must win. With a biological hierarchy, the weakest individuals can remain without a share of prey, but this is the logic of natural selection: the weakest individuals should not leave offspring in order to avoid species degradation. The disturbing factor for physical strength as an order parameter of the system cannot arise as a genetic mutation. Here we are talking about the fact that a physically weak individual can successfully resist a stronger individual. This phenomenon is unnatural in the sense that it contradicts natural selection. Such actions of weak individuals can appear only as their lifetime invention, including the use of artificial means that they can use along with fangs, fists, etc. In other words, the ancestors of man had stood out from all primates in that they acquired the ability to fight each other in arms. A physically weak individual could defeat a powerful leader through a good choice of weapons, just as the biblical David defeated the giant Goliath. This conclusion can be reached not only by hypothesis, but also by purely logical reasoning. For this it is necessary to use the approach to the study of evolution proposed by Hegel. ${ }^{11} \mathrm{He}$ spoke development as a process governed by his "germ": being-in-itself. Here, the most important point is that the highest stage of development - being-foritself - has the same content as the original stage but in a different form. This brings us to the second most important point: when studying evolution, it is necessary to consider it from the highest stage to the lowest. Having established the content of the highest stage, one can draw logical conclusions (and not hypotheses!) about the content of the initial stage of the process. New abilities acquired by living beings are not lost by them. Therefore, the ability of hominids, which has become a disturbing factor as their physical strength became an order parameter and thus destroyed the biological hierarchy, exists in modern humans.
However, in order to isolate this ancient ability from many later human abilities, it is necessary to conduct a kind of "excavation" of its need-ability structure. The situation is clarified by the fact that, firstly, this ability concerns the physical struggle (fight) among individuals. Secondly, it appeared only in human ancestors, whereas in other primates this ability did not emerge because, in bands of modern apes, there is still a biological hierarchy. Therefore, comparing the characteristic features of the struggle among modern apes with similar features of struggles among modern people, we will see what kind of new ability the most ancient of human ancestors had found. A key observation, showing how the struggle among apes differs from the struggle among people, is the observation made by W. Kohler. This ingenious observer noticed that apes in a game can threaten each other with sticks but, if it comes to a real fight, they discard their sticks and fight with their fists and fangs. ${ }^{12}$ Apes are not capable of armed struggle against each other, while people practice it constantly. Here is the key to the behavior of hominids that have embarked on the path of humanization! Using the position of Hegel concerning the identity of the content of evolution's initial and higher stages, we can conclude in a strictly logical (rather than hypothetical) way, that the hominids who became the ancestors of man were distinguished from all primates by mastering the skill of armed struggle against each other.

\section{The initial historical act}

The answer to the question surrounding the content of the last historical act opens up a way of understanding the content of the initial historical act. In the armed struggle, many members of the band could claim to be the first entitled to eat prey, inevitably leading to fights. However, in conflicts that only uses natural means of attack and defense, the individual who loses the fight feels a threat to his life and stops fighting. This is why fights in the animal kingdom rarely led to death. In contrast, in an armed struggle, no participant instinctively feels which blow could be deadly. Armed struggle literally forced our animal ancestors to eradicate their animal instincts and build a new system of mutual relations. The logic of things in this case unambiguously suggests that the way out consisted of the peaceful sharing of prey among all members of the hominid band. Ape-like creatures perform humanlike actions of sharing prey - this is "the initial historical act." The logic of things here is only a hypothesis. But to understand the content of the first historical act, Hegel provides a most valuable reference point, which allows us to replace the hypothesis about the emergence of the sharing of the prey, with a strictly logical conclusion.

Nowadays, people rarely make a product to meet their own needs. They produce things which are unnecessary for them and receive the items of their needs in exchange for these products. Exchange is the most developed form of sharing, when people share different products of their labor with each other. The highest stage of evolution - modern social relations - involves the countless acts of sharing in which people share the products of their Labor (things, ideas, works of art, etc.) with each other. Using the principle of the content identity of the initial and higher stages of evolution, we conclude, purely logically (not hypothetically) that the initial social relation was the peaceful sharing of prey among members of a hominid band. In this act of anthroposociogenesis, man and social relations emerged together. Sharing is an act of humaneness. How else could a human being emerge if not due to an act of humaneness? By definition, humans could only emerge from an act of humaneness, rather than from collective hunting or production. The presence of the program of world history in the act of sharing manifests in the fact that it became the ground upon which two phenomena grew: 1) the human need-aptitude structure and 2) permanent struggle among communities. 


\section{The formation of the needs-aptitude structure of man}

Because physical force ceased to be the only factor determining the outcome of a struggle between males, the strongest male lost the unconditional right to own females, who then got the opportunity to favor their preferred males. Due to this, females were turning into women, and males were turning into men. Under these circumstances, the prey and loot of hunters and warriors acquired a double meaning: it became the subject of satisfying the need, as well as a means of gaining women's favor. In other words, with the onset of sharing, a powerful engine of progress - the sublimation later discovered by Freud - was started. In the acts of sharing, needs were formed which had a social nature. Obviously, human ancestors involuntarily expressed their approval (with sounds and gestures) to those hunters who brought prey to share. The general law for the development of the need-and-ability structure is that the new ability becomes a new need. So, for example, the ability to move has given rise to the need for movement; from the ability to hear a need for sound-perception has arisen (complete silence is painful for a person) etc. Likewise, the ability to accept approval turned into a need for approval which, for some people, became a need for glory. Darwin noted the great importance of the desire for lapproval for the progressive development of communities. He wrote: "There is another and much more powerful stimulus to the development of the social virtues, namely, the praise and the blame of our fellow-men". ${ }^{13}$

Unlike the need for food, the need for glory is "insatiable." It encourages the improvement of tools and instruments even when food is abundant. The ability to improve tools and instruments has created another new need: the need to engage in favorite activities "out of a love for art." For example, for some members of the community, making stone tools became a favorite activity, while others favored fishing, etc. With the advent of sharing, the following question arose: according to which principle does one share means and objects of needs among members of the community? The ability to change the distribution principle led to the need for righteous society arrangement. Here we do not speak of the conflict from which fighters obtain more objects of needs; here we speak of an absolutely "unselfish" need for justice which drives the fighters (revolutionaries, missionaries etc.) towards other people's happiness. Therefore, we can see that the human needs-aptitude structure sprang up out of prey distribution. In addition to primary needs (food, self-protection etc.) and secondary, functional needs (movement, sound perception etc.), there emerged a third class of needs that may be called "leading needs" (fame, favorite work, righteous society arrangement etc.). These are characterized by the fact that they determine human strategy in terms of vital activities and they "lead" people throughout their lives.

\section{The emergence of socially-natural selection}

Another very important component of the historical process program, laid down in the initial historical act, is a permanent struggle among communities. In the animal world, there is no permanent struggle among bands because there is no factor that would create significant superiority in the combative behavior of some bands over others. With the advent of sharing, a factor appeared that increased the variance of the fighting capacity of communities: the different principles of sharing prey in different bands. Biological hierarchy is the result of biological heredity, while the principles of sharing were established by the members of the band during their lifetime, and these principles were the product of the social creativity of those members. Therefore, these principles were significantly different in different bands. In some communities, even weak individuals survived, while in other communities, this could fail to happen. In the continuous struggle of communities, those with the most humane principles of division eventually became most successful, provided that among the weaker members of the community there were inventors and old people who taught young people. Moreover, armed struggle changed the very concepts of strength and weakness. The humanity of the distribution principle brought about an increase in combat capabilities. A "natural selection" took place in communities, with the most humane distributive principles and the weeding out of less humane communities. So, slowly but surely humanity was humanizing. Nobody taught people humanism - neither religious figures, nor philosophers - people were becoming people by virtue of the fact that, in social relations (in the relations of sharing and exchange), there was the potential for progressive humanism. Therefore, it is natural to call this kind of humanism social-humanism, i.e., humanism that results from social relations, as such. This is an objective humanism which is not subjectively sought by anyone but arises from the fact that the communities with sharing principles, that spontaneously have proved to be the most humane, remain on the stage of history. As a consequence, it is natural to call group selection in the struggle of people's communities, social-natural selection.

\section{The law of socially natural selection}

The famous sociologist Pitirim Sorokin wrote about the ideal distributive principle: "The principle that is so necessary for a prosperous society says:" To each according to his abilities (especially innate)". ${ }^{14}$ A clarification is needed here. For this principle to work for the prosperity of society, it must emphasize productive ability. Taking this into account, the law of development of society (the law of social-natural selection) can be formulated as follows: "In the course of group natural selection, the winners are communities with the distribution principle closest to the ideal principle" To each according to his productive abilities ". This principle is ideal because it provides the greatest return on the activities of each member of the community, i.e. it ensures the best development of the productive forces. Here we mean not only and not so much a reward on merit, but rather that the distribution of vacancies in situations where their number is less than the number of candidates for these vacancies should be carried out in accordance with the productive abilities of candidates shown by them in the course of productive activities. In fact, the distributive principle is formed spontaneously under the influence of many random factors, but in some communities it is closer to the ideal principle, in others it is further from it.

The former will have more developed production, and, other things being equal, they will have a better chance of winning in socially natural selection. This principle can be formulated differently. Any economically expedient (that is, rational) action increases the number of items of need. Therefore, rational (economically expedient) actions contribute to the satisfaction of people's needs, that is, they are humane. Conversely, any humane action helps people to satisfy their actual needs and, therefore, gives them the opportunity to focus on the realization of their productive abilities. In this respect, every humane action is economically expedient (reasonable). "Everything humane is reasonable, everything reasonable is humane" - this is another formulation of the optimal distributional principle. In the conditions of modern civilization, this formulation is the most important reference point not only for the internal political and economic strategy, but also for the foreign policy of the community.

\section{Result}

The application of a systematic approach to the problem of the origin of the human way of life has yielded a number of non-trivial 
results. The primary outcome is purely methodological. This result consists in dividing the general problem into three sub problems with specific solutions.

- As a model of behavior of members of a band of hominids, anthropologists consider the system of biological hierarchy The order parameter of this system is the physical strength of individuals. As a primary subtask, the systems approach identifies the question: what disturbing factor deprived the physical strength of individuals of the status of an order parameter and brought the system of biological hierarchy into a state of instability - to a point of bifurcation. In other words, what actions "invented" by the hominids became the last animal act.

- The second question: what actions of hominids brought this system out of the point of bifurcation and created a qualitatively new system - a system of social relations (social hierarchy). In other words, what actions of hominids became the initial historical act from which the history of mankind began?

- The third question related to understanding the emergence of the human way of life: what is the mechanism of humanization, i.e. mechanism of evolution from human ancestors who performed the initial historical act to homo sapiens.

The answer to the question about the disturbing factor in the biological hierarchy is of fundamental scientific importance. The conclusion that such a factor was the new ability of human ancestors to wage an armed struggle with each other indicates not only the factor that destroyed the biological hierarchy, but also explains the reason for the emergence of bipedalism. Human ancestors began to walk on two legs in order to free their hands for the use of weapons of armed struggle with each other. Another fundamentally important result is the conclusion about the peaceful division of booty as an initial historical act. The practice of division has become the source of the human's need-ability structure. The difference in the principles of division in different communities led to a large scatter of the levels of community combat capability and to a permanent struggle between communities for the best habitats. The conclusion about the advantage of communities with the most humane principles of division in the development of productive forces leads to the conclusion that the mechanism of humanization of communities is the socially-natural selection of the most combat-effective communities, i.e. communities with the most developed productive forces. Two formulations of the law of social and natural selection are given. This result is important not only from a scientific point of view. It is also important for political ideology.

\section{Discussion}

The reliability of the above results can be confirmed by several methodological remarks. These results make it clear why the problem of the origin of bipedalism became "one of the most persistent mysteries of paleoanthropology" (D. Gebo); "a truly 'cursed question' of paleoanthropology" (L. Vishnyatsky). Speaking on the absence of an explanation for the origin of bipedalism, R. Mayer writes: "The dual condition was caused by a certain behavioral stimulus. What that could be will continue to be investigated by paleoanthropologists". ${ }^{15}$ It is true that bipedalism was not an end in itself, but "was caused by a certain behavioral stimulus". But R. Mayer, like D. Gebo and L. Vishnyatsky, considers the problem of the emergence of bipedalism as a problem of paleoanthropology. The paleoanthropological approach to understanding the origin of the human way of life is well described by B. Campbell. He writes: "We will try to trace the evolution of the entire human being as a social animal. We will move from studying the evolving human body to looking at the evolution of human behavior and human society". But it is not the case that as a result of anatomical changes and the emergence of new tools, the human way of life was formed, but on the contrary, anatomical changes and new tools arose as a result of the formation of the human way of life. The movement from paleoanthropology to human behavior and society does not provide observational data for understanding anthroposociogenesis (the joint origin of man and society). It is no accident that, with this direction of movement of research thought, the fact that humans are radically different from other primates, widely practicing armed struggle with each other, dropped out of the field of vision of scientists. On the contrary, a systematic approach to the problem of transforming the system of biological hierarchy into a social hierarchy highlights the role of intraspecific warfare already at the first stage - at the stage of searching for the disturbing factor of the order parameter of the biological hierarchy. At the same time, the reason for the emergence of bipedalism is explained: the release of hands from locomotor function was required for hominids to manipulate the weapons of intraspecific struggle.

Mastering the skill of armed struggle can be called, without exaggeration, the Great Hominid Revolution, since through this "invention," our ancestors challenged natural selection. Using it, they first overthrew the despotism of physical force and, secondly, made bipedalism necessary. Russian scientist A. Markov writes about the choice of the most convincing hypothesis concerning the origins of bipedalism: "Entire articles and even books are devoted to arguments in favor of each of these hypotheses, but none of them has direct evidence. In such cases, in my opinion, it is necessary to give preference to hypotheses that have additional explanatory power, that is, they explain not only bipedalism, but at the same time some other unique hominid features. In this case, we will have to make less controversial assumptions". ${ }^{16}$

The concept of the origin of bipedalism proposed here, firstly, explains two most important features of the evolution of hominids: the emergence of bipedalism and the destruction of the biological hierarchy. Secondly, it is not a hypothesis, but a logical conclusion from the current state of affairs. In connection with the last fact, it is necessary to emphasize the great heuristic potential of the approach to the study of evolution developed by Hegel. It is easier to obtain information about the later stage of evolution than information about the initial stage. Using this information, we make a logical conclusion about the content of the initial stage of evolution. In particular, what new system of relationships has arisen instead of the biological hierarchchi can be understood by examining the system of relationships of modern people. Our way of life is the division of products of production in the form of an exchange of them. Consequently, in place of the biological hierarchy, a peaceful division of prey arose among all members of the hominid's band. The reliability of this conclusion is confirmed by the fact that paleoanthropologist, using the classical approach to the problem of human origin, also came to it. So the book of the outstanding anthropologist R. Leakey the Making of Mankind has a section called Sharing as a way of life. "Way of life" is a very accurate description of the sharing, which refers not only to the stage of the birth of mankind, but also to the present. R. Leakey writes: "I believe that the food-sharing hypothesis is a very strong candidate for explaining what set early Hominids on the road to modem man". ${ }^{17}$ However, R. Leakey's hypothesis is only a hypothesis; while the systems approach in combination with the Hegelian theory of evolution allows us to show the role of sharing not as a hypothesis, but as a strict logical conclusion. The great idea of considering group selection as a mechanism of mankind's humanization belongs to Charles Darwin. He wrote: "At all times throughout the world tribes 
have supplanted other tribes; and as morality is one element in their success, the standard of morality and the number of well-endowed men will thus everywhere tend to rise and increase". ${ }^{13}$ But the social instincts of anthropoids have created a biological hierarchy that is quite consistent with the logic of natural selection.

And the "last animal act" consisted in the destruction of the social instinct created by natural selection. The elimination of this instinct opened the way to the initial historical act (the sharing of a prey), "which served as the basis for the development of moral feeling." Here it is appropriate to recall the words of Hegel that "the spirit does not come from nature by natural ways." The spirit occurs contrary to natural selection, for both the last animal and the first human acts are contrary to the logic of natural selection. It is interesting that, on the issue of the origin of the spirit, the great philosopher who proceeded from universal philosophical principles, turned out to be closer to the truth of the great biologist, who proceeded from the law of natural selection. Obviously, Darwin could not make use of such integral concepts as the production and distribution principle, because he did not abandon his attempts to explain the origins of man through natural selection. A. Wallace denied the possibility that natural selection generated humanity. He said that man's abilities in mathematics and music could not have emerged as a consequence of natural selection because the survival of the species would never be dependent upon these characteristics. "The special faculties... clearly point to the existence in man of something which he has not derived from his animal progenitors - something which we may best refer to as being of a spiritual essence or nature". ${ }^{19}$ Darwin contested Wallace's arguments: "I cannot, therefore, understand how it is that Mr. Wallace maintains, that "natural selection could only have endowed the savage with a brain a little superior to that of an ape."'13

Of course, in this dispute between the great biologists, it is Wallace who is correct. The fact of the matter is that in human vital activity, the obtained skills took on special significance. These skills are not transmitted genetic inheritance. Animals come into the world fully armed with instincts, but each new generation finds the world almost the same as it was for their predecessors, time and again having to start afresh. In contrast, each new generation of people lives in an increasingly developed social world which leads to extremely rapid human development, compared to the development of the animal world. Natural selection in its essence cannot control the development of human society because the ability to use tools is not a heritable trait. The purely physiological birds' capability for singing is inheritable while the ability to sing an opera aria is not. Natural selection forms inflexible, purely biological instincts, while flexibility of the needsand-aptitude structure is necessary for learning to use tools. Thus, social-natural selection leads evolution in a direction which is opposite to the one of natural selection. The concept of socio-natural selection assumes, as its basis, Darwin's idea of group selection. This concept considers the integral characteristics of communities as a criterion for selection: the distribution principle and the level of production development achieved through the social inheritance of productive forces and the means of production. It is interesting and instructive to compare the concept of socially natural selection with other concepts of the development of society, in particular with Marxism. However, these comparisons are beyond the scope of this article. But it is made in my book A Theory of Human Origin and Evolution Based on Hegel's Philosophy. ${ }^{10}$

\section{Conclusion}

This article describes solutions to two famous problems at once: human origins (more precisely, the human way of life) and bipedalism.
This success is due to a successful choice of methodology: the systems approach and the concept of evolution, developed in Hegel's philosophy, greatly simplify the understanding of human genesis. As for the origin of bipedalism in humans, this problem is part of the first more general problem and is easily solved along with it. It should be especially emphasized that the solutions obtained are not hypotheses, but strict logical conclusions from reliable material provided by primatology. This fact shows the great heuristic potential of the systems approach and the Hegelian concept of evolution. A more detailed description of this fruitful methodology is given in my aforementioned book.

\section{Acknowledgments}

None.

\section{Conflicts of interest}

The author declares that there is no conflict of inertest.

\section{Funding}

None.

\section{References}

1. Porshnev B. On the beginning of human history. "Mysl". Moscow. 1974.

2. Gebo D. Climbing, brachiation, and terrestrial quadrupedalism: historical precursors of hominid bipedalism. Am J Phys Anthropol. 1996;101(1):5592.

3. https://antropogenez.ru

4. Theories of bipedalism. encyclopedia Britannica. Inc Leakey L. Adam or ape, publisher: schenkman books. 1982.

5. Leakey L. Adam or ape. Publisher: schenkman books. 1982.

6. Marx K. Theses on Feuerbach, Marx \& Engels collected works. Lawrence \& Wishart electric book. 2010

7. Semenov Yu. How humanity arose, Ed 2nd, state public historical library of Russia, Moscow. 2002:45-46.

8. Rutherford F, Ahlgren A. Science for all Americans.

9. Edey M. The missing link. Time-Life Books, New York. 1972.

10. Peruanskiy S. A theory of human origin and evolution based on Hegel's philosophy. Cambridge Scholars Publishing, Cambridge. 2020.

11. Peruanskiy S. Basic theory of human origin based on Hegel's philosophy. Hegel-Jahrbuch. 2019;1:pp 559-565.

12. Kohler W. Intelligence tests on great apes. Verlag von julius springer in Berlin. 1921

13. Darwin C. The descent of man and selection in relation to sex D. Appleton and Company, New York. 1889.

14. Sorokin P. Man civilization society. Politizdat, Moscow. 1992.

15. Mayer R. The prehistory of humanity. AST Astrel, Moscow. 2006.

16. Markov A. Human evolution: monkeys, bones and genes. Corpus, Moscow. 2013.

17. Richard L, Making of Mankind. E P Dutton and company, New York. 1981.

18. Darwin C. The descent of man, and selection in relation to sex. John Murray, London. 1871.

19. https://en.wikisource.org/wiki/Darwinism_(Wallace)/Chapter_XV/ 